\title{
Information in Crisis: Health \& technology-related information behaviors of parents in emergency departments
}

\author{
Lisa M. Given, PhD \\ School of Information \\ Studies \& RIPPLE \\ Charles Sturt University \\ Wagga Wagga, Australia \\ lgiven@csu.edu.au
}

\author{
Rebekah Willson \\ School of Information Studies \\ \& RIPPLE \\ Charles Sturt University \\ Wagga Wagga, Australia \\ rwillson@csu.edu.au
}

\author{
Lauren Albrecht \\ Paediatrics \& Nursing \\ University of Alberta \\ Edmonton, Canada \\ lauren.albrecht@ualberta.ca
}

\author{
Shannon D. Scott, PhD \\ Nursing \\ University of Alberta \\ Edmonton, Canada \\ shannon.scott@ualberta.ca
}

\begin{abstract}
This research examined the information behavior of parents (including legal guardians) during an emergent health situation with a child. Although many studies examine health-related information behaviors, very few explore health consumers' information practices during moments of health crisis. This study explored parents' information needs, source use, and source preferences during a visit to the emergency department. An online questionnaire was administered using iPads given to 897 parents with children at one of 32 participating general emergency departments (ED) across Canada. Before taking their child to the ED, only $38.8 \% \quad(n=348)$ of parents looked for information; those who did search looked most frequently for information about specific symptoms or severity of illness. Prior to visiting the ED the sources most frequently accessed were the internet and direct contact with healthcare professionals. At the emergency department, parents' information needs centred on immediate concerns, including explanations of their child's illness, treatments, and care instructions. Household income, education level, and parents' age were factors that affected information seeking in emergent health situations. Overwhelmingly, speaking to a healthcare professional in person is the typical and preferred way to obtain health information when facing a health crisis involving a child. The results have implications for how and when healthcare information is shared; the findings add to the limited research on parents' information behavior, particularly their roles as information proxies for their children.
\end{abstract}

\section{Keywords}

Information behavior; Health crises; Parents

ASIST 2016,October 14-18, 2016, Copenhagen, Denmark.

Authors Retain Copyright.

\section{INTRODUCTION}

Patients and other healthcare consumers access various information sources to learn about symptoms and diagnoses, to guide decisions on treatments and care, and to gain emotional, financial, or other support. Health-related information technologies, such as websites, social media tools, and web apps, play important roles in individuals' health-related information seeking. Over several decades, information science researchers have explored the broad array of sources, technologies and personal situations that inform individuals' health-related information behaviors. Johnson and Case (2012) present a detailed overview of research on health information seeking, including influences from other disciplines (such as nursing and medicine). However, very few studies explore information behaviors during emergent or traumatic healthcare situations. Similarly, studies of healthcare consumers typically focus on the experiences of the patients, themselves, and often only in relation to ongoing or chronic health conditions (such as cancer or diabetes); very little research explores the experiences of patient 'proxies' or those individuals who seek information to support or make decisions about another person's care.

The results presented in this paper detail the information behaviors of parents (including legal guardians) when taking their child to a hospital emergency department. The results provide unique insights into the types of information sought, the information platforms used, and parents' views on the information needed to guide decision making during emergency care situations involving children. This research is part of a larger project that examined how health research about pediatric emergency care is put into practice; the project was conducted in 32 emergency rooms across Canada and also gathered data from healthcare providers. The results presented here explore parents' information needs, source preferences, and information priorities related to their child's health; these elements are identified as valuable starting points in examining parent and family engagement in child health decision making (Canadian Public Health Association, 2008). The research questions addressed by this research were: 1) What information, if 
any, do parents seek before taking a child to the emergency department? 2) What are parents' information behaviors during the visit to the emergency department? 3) What information sources do parents typically use and/or prefer to use when seeking health information?

\section{LITERATURE REVIEW}

\section{Consumers' Health Information Behavior}

A great deal of research examines the information behavior of users of health information - or what are often called healthcare "consumers." While, in the past, health information was managed primarily by healthcare professionals, consumers' information seeking continues to grow; there is now more concern with health and preventive medicine and a substantial increase in the number of health information websites aimed at the general public (Johnson \& Case, 2012, p. 19). Technology has also given individuals access to vast amounts of information and now shapes health consumers' information behavior (Case, 2012, p. 340). This shift in access is also a shift in responsibility, with individuals more responsible for and more burdened with making decisions about their treatment (Johnson \& Case, 2012, p. 163). As a result, health literacy - individuals' information base, as well as their abilities to access, evaluate, and use that information (Diviani, van den Putte, Giani, \& van Weert, 2015) - has become an important skill and an important topic of study (Johnson \& Case, 2012, p. 9-12). While health literacy is now an important skill for consumers, the healthcare system has not fully evolved, in parallel, to facilitate discussions between healthcare providers and consumers about this information.

As technology changes, and as there is increased access to health information, health literacy is an integral part of being able to evaluate and trust online health information (Diviani et al., 2015). Some researchers note that the internet has changed how people search for health information, often being the first choice when seeking information (Johnson \& Case, 2015). Individuals find a great deal of health information online, making the internet an important information source, whether for documentary sources or for advice from peers or health professionals (Johnson \& Case, 2012, p. 80-84). Social networking sites, for example, allow individuals to connect and have ongoing engagement with communities and site features can facilitate the flow of complex information (Johnson \& Case, 2012, p. 67-68). Mobile and wearable technologies (e.g., smartphone apps, activity trackers, etc.) now provide access to real-time personal health information and ways to track information longitudinally. In general, health information consumers rely on a wide variety of formal and informal information sources (Genuis, 2012). However, as technologies continue to make information readily available, many people need guidance on how best to manage that information and determine what information can be trusted (Diviani et al., 2015; Johnson \& Case, 2012). Finding and using health information is particularly difficult in emergent situations, when consumers have little time and/or need to make decisions quickly, during stressful situations. Additional research is needed to understand fully the implications of information behaviors and technology use in moments of health crisis. This paper reports results of a large-scale, national study that explores this issue.

\section{Information Behavior During Crisis Situations}

At present, there is limited research on individuals' information behaviors and/or technology use during emergency situations. Published studies focus on information seeking and technology use during natural disasters (e.g., Lopatovska \& Smiley, 2014; Pang, 2014), as well as the information needs and seeking activities of survivors of intimate partner violence (Dewdney, Harris, \& Lockerby, 1996; Westbrook 2008a; 2008b; 2009). What is lacking is research about individuals' information behavior in emergent health situations.

The few studies that do explore information behaviors and technology use in emergency departments focus on the experiences of healthcare practitioners (e.g., Ayatollahi, Bath, \& Goodacre, 2013; Hope \& Zhang, 2015; Johnson et al., 2011; Reddy \& Spence, 2008). Two studies explored consumer-related information use in emergency departments; however, these focus on patient education (Joshi, Weng, Lichenstein, Arora, \& Sears, 2009) and information provision (Koonce, Giuse, \& Storrow, 2011), rather than individuals' actual information behaviors during moments of health crisis. Two additional studies explore consumers' experiences during public health scares. One examined students' information seeking during an E. coli outbreak; the results showed that the internet was an important source for passive reception of information and that social media were not viewed as suitable or reliable information sources (van Velsen, van Gemert-Pijnen, Beaujean, Wentzel, \& van Steenbergen, 2012). The second study examined parents' information needs and source use during a Measles-Mumps-Rubella vaccine scare; this study found that parents' information needs increased, as did the importance of trustworthiness as an important factor in determining which health information sources to use (Guillaume \& Bath, 2004). However, none of these studies explored proxy information seeking, emergency room situations, or children's emergent healthcare needs.

\section{Proxy Information Seeking}

Proxy-based information seeking (also referred to as intermediary, surrogate, or gatekeeper seeking) can be an important aspect of finding relevant information. While early explorations of proxy information seeking within information science involved librarians acting on behalf of patrons, over the years the concept has expanded and changed. Proxy information seeking is now understood to take place between any individuals, with "information proxies" those individuals who are "making contact with or interacting with information sources through the initiative of another agent" (McKenzie, 2003, p. 27). Proxy connections can include referrals to information sources by 
proxies, as well as proxies acting as intermediaries or gatekeepers, regularly seeking information on behalf of others (McKenzie, 2003). Before referring information to others, proxies filter information according to certain criteria, with the purpose to transmit it ( $\mathrm{Lu}, 2007)$. One group that regularly seeks information on behalf of others is parents, who seek information on behalf of their children for a range of everyday life decisions (e.g., choosing school subjects; purchasing clothes), including for health information (Case \& Johnson 2012, p. 68).

\section{Parents' Decision-Making Activities}

Despite the amount of research available on the information behavior and decision-making activities of different groups, research on parents is lacking. There have been some studies on specific groups of parents, such as the information needs and sources used by homeless parents (Hersberger, 2001) or affective experiences of stay-at-home mothers (Fisher \& Landry, 2007). Studies by Walker (2009, 2012) have examined the information behavior and decision-making of parents, generally; the results show that parents use a variety of context-based techniques to make informed decisions (Walker, 2009). Common approaches used by parents include relying on "gut feeling" (i.e., using tacit knowledge to interpret data in conjunction with personal values and trust in the information), as well as searching for specific answers to questions (Walker, 2009, p. 56). A gut reaction is important not only in parents' dayto-day decision making, but also when deciding whether or not to take their children to emergency departments (Albrecht, Hartling \& Scott, in press). Parents commonly engage in satisficing behavior, evaluating and validating information through familiar and trusted sources, in ways that are comfortable to them (Walker, 2012). Socioeconomic status is an important factor influencing parents' interactions with information, particularly in trusting healthcare professionals (Walker, 2012).

There are few studies in information science examining the information behavior of parents, or their decision-making, relating to their children's health. However, studies from medicine and other health disciplines have examined parents' decision-making, finding that the process is complicated and influenced by many factors (Jackson, Cheater, \& Reid, 2008; Lipstein, Brinkman, \& Britto, 2012). Simply providing information to parents is not an effective way of assisting making informed decisions (C. Jackson et al., 2008). Jackson and colleagues (2008) reviewed the health decision-making literature and found that parents need: quality sources available in various formats from trustworthy sources, tailored to the individual; the opportunity to talk to and share information with others in the same situation; and, to be in control of the level of preferred involvement in making decisions. Similarly, Lipstein and colleagues (2012) reviewed the literature and found that most parents want to be involved in making health decisions for their children, sharing that responsibility with healthcare professionals. However, literature in the health disciplines that reference the terms "information needs" and "information seeking" do not typically document findings from information science research or base analyses on information behavior theories.

\section{Parents' Health Information Needs and Seeking}

Despite the lack of information science research in this area, health research shows that access to health information is one of the major needs of parents of young children (Nicholas \& Marden, 1998), particularly when children are ill or have ongoing medical conditions. Information needs tend to focus on the illness itself, as well as its treatment. Studies indicate that parents of chronically ill children, for example, have an overwhelming desire for more information about their children's condition and treatment, which can be linked to a desire for certainty and normality (Fisher, 2001). Parents of chronically sick children have varied information needs that can change over time, relating to diagnosis, health management planning, and prognosis (Hummelinck \& Pollock, 2006). One study of parents of children with disabilities (chronic illness) in Kuwait found that information needs of parents are highest at the time of diagnosis, particularly for information about how best to educate children (Al-Daihani \& Al-Ateeqi, 2015). Families with children who have had mild head injuries (as an acute illness) required information about the injury and how to provide care, as well as support for dealing with the emotional burden of caregiving (Falk, von Wendt, \& Klang, 2008).

Many parents actively seek information to meet their information needs; however, resisting information due to fear of its negative impact is another way some parents cope with ill children (Hummelinck \& Pollock, 2006). Some parents seek information to identify symptoms and determine if a visit to the doctor is necessary (Ingram, Cabral, Hay, Lucas, \& Horwood, 2013). For parents whose infants had positive screens for medical conditions, they sought information before meeting with healthcare professionals (DeLuca et al., 2012). Overwhelmingly, these parents searched the internet for information. Mothers of young children, for example, look online when needing information about pediatric conditions, as well as general information on parenting and development (Bernhardt \& Felter, 2004). In examining where parents get health information, one study found the vast majority of parents use the internet to search for health information, both for themselves and for family members (Bianco, Zucco, Nobile, Pileggi, \& Pavia, 2013). Parents with more education tend to use the internet more frequently to find health information (Bianco et al., 2013). However, parents of pediatric patients trust their doctors more than the internet as an information source (Wainstein, SterlingLevis, Baker, Taitz, \& Brydon, 2006).

Parents have different health information source preferences. Despite the internet being an important source 
for parents, many prefer in-person contact. Parents in the UK preferred receiving health information via one-to-one verbal communication with healthcare professionals, supplemented by accessible written materials (Jackson, Baird, Davis-Reynolds, Smith, Blackburn, \& Allsebrook, 2008). Kuwaiti parents with children with disabilities preferred getting child health information from doctors and books and least preferred getting information from online support groups and social media (Al-Daihani \& Al-Ateeqi, 2015). For health and development information related to parenting, the internet, drop-in programs for parents and children, books, organized play groups, classes and information sessions were identified as the most preferred modes to access information (Devolin et al., 2013). However, parents looking for health and development information for young children often find informal supports as more important and valuable than formal supports (Devolin et al., 2013). Internet sources have the potential to increase parents' anxiety about a child's medical condition (DeLuca, Kearney, Norton, \& Arnold, 2012). As noted by Bouche and Migeot (2008), the internet is a supplement to, not a replacement of, professional medical care.

\section{Parents as Proxy Seekers of Health Information}

Proxies are important in health information seeking with many information seekers looking for information on behalf of someone else (Johnson \& Case, 2012, p. 68), often, without being asked (Abrahamson \& Fisher, 2007). In health contexts, parents take on a very special proxy role; they do not simply act as information agents, but they must also make decisions for their children because they are legally and morally obligated to do so. Further, the emotional connection between parent and child has the potential to make intermediate healthcare decision making more complicated. For example, parents may choose to ask others to search for or filter information to allay their own distress about a child's possible condition (DeLuca et al., 2012). While parents are frequently gatekeepers of information for children (Koehly et al., 2009), they may lack the information assessment and technology skills necessary to act fully in a proxy role (Johnson \& Case, 2012, p. 68). Acting as a proxy is vital in crisis situations, particularly with young children and/or those who are not able to speak for themselves when receiving emergency care. To date, studies have not explored parents as information proxies in emergency room environments.

\section{RESEARCH DESIGN}

A survey methodology was used to explore parents' information needs, source preferences, and information priorities related to their child's health. An online questionnaire was developed (and pilot tested) for implementation in 32 hospitals in nine provinces and one territory across Canada. Data collection was conducted using iPads distributed to parents during their visits to emergency departments (EDs) to seek care for their children; each questionnaire took approximately 10 minutes to complete. Participants were offered the questionnaire in their language of preference, English or French (Canada's two official languages). Research ethics approvals (43 in total) and on-site, operational access approvals (50 in total) were obtained from participating research institutions, health regions, and hospitals prior to data collection.

The questionnaire included 26 questions covering the following topics: demographic information (12 questions); information about the current visit to the ED (5 questions); healthcare information needs ( 7 questions); and information source preferences (2 questions). Question formats included single and multiple choice responses, sliding scales, and drag and drop boxes in which responses could be dragged to a new column and rank ordered, along with some openended response categories. For each question, parents could give multiple answers for some questions (e.g., sources used). When participants selected "other" as a response, they were given the opportunity to provide an answer, which were added to the dataset.

\section{Recruitment and Data Collection}

Recruitment of parent participants took place on-site in EDs using an informed consent process. Members of the research team travelled to each site and approached parents who were at various stages of their visit (e.g., newly arrived; waiting for results; waiting to speak with a healthcare practitioner). Interested parents were provided with an iPad to review the ethics materials and complete the questionnaire. The survey was conducted with a convenience sample of parents who brought their child to one of the EDs for medical attention at some point during the 11-month data collection period. In total, 1,099 parents were approached and agreed to review the information sheet. Of those, 974 parents consented to participate and 897 questionnaires were completed.

\section{Participants}

Of the 897 parents who completed the survey, $75.8 \%$ $(n=680)$ were female and $24.2 \%(n=217)$ were male. Ages were collected using age ranges, with the youngest participants "under 20" and the older in the "65-69" category. The mode age range was 35-39 years old $(24.3 \%$, $\mathrm{n}=218$ ). Information about the highest level of education attained by parents was captured, varying from partial completion of secondary school to attaining a graduate degree. The most frequent educational level was "college, pre-university, or non-university certificate/diploma" chosen most frequently $(29.6 \%, \mathrm{n}=265)$, followed by "High school diploma or equivalent" $(22.8 \%, n=204)$. Average household income varied from "under $\$ 25,000$ per year" to "over $\$ 100,000$ per year," with "over $\$ 100,000$ per year" chosen most frequently $(19.9 \%, n=178)$, followed by “\$50,000-\$74,999 per year" $(18.0 \%, n=161)$.

Demographic questions were also asked about the children needing care in the ED; ages ranged from 0 to 18 years, with an average age of 6.7 years and a mode of 2 years. A minority of children needing care had a known medical 
condition $(6.5 \%, \mathrm{n}=58)$; the vast majority came to the ED without a known medical condition $(93.5 \%, n=838)$. The three most frequent medical concerns presented were fever $(17 \%, \mathrm{n}=152)$, vomiting $(10 \%, \mathrm{n}=90)$, and stomach pain $(10 \%, n=90)$. Parents were also asked if the child requiring care had regular/routine health check-ups. The majority of children did have medical check-ups regularly $(75.1 \%$, $\mathrm{n}=674)$, while $22.3 \%(\mathrm{n}=200)$ did not. Only $2.6 \%(\mathrm{n}=23)$ of parents were unsure about their child's check-up regularity.

\section{Data Analysis}

Descriptive statistics were generated in SPSS (v.21) and free text responses (i.e., "Other" categories) were analyzed thematically. A biostatistician conducted linear regression models and binary logistic regression models using SAS (v.9.3). Regression models determined associations between independent (i.e., demographic) and dependent (e.g., information needs, source preferences) variables.

\section{RESULTS}

The results are divided into those documenting parents' information needs and those outlining the types of sources parents used or preferred. Parents were asked if they looked for information about their child's health prior to visiting the ED. Of the parents who participated, 60.7\% $(n=549)$ did not look for any information prior to the visit.

Table 1 presents parents' responses to the follow-up, "Why not?," which ranged from time concerns, to source preferences, to access issues. "Other" reasons included not thinking it would be an emergency $(n=2)$, family doctor unavailable $(\mathrm{n}=2)$, looking for information increased stress/fear $(n=2)$, not being present $(n=1)$, and not thinking about looking for anything $(\mathrm{n}=1)$.

\begin{tabular}{|l|l|}
\hline Reason & $\begin{array}{l}\text { \% (n) } \\
\mathbf{n}=\mathbf{5 4 9}\end{array}$ \\
\hline $\begin{array}{l}\text { Did not have time because in a hurry } \\
\text { to get to the emergency department }\end{array}$ & $45.2 \%(248)$ \\
\hline $\begin{array}{l}\text { Prefer to obtain information at the } \\
\text { emergency department }\end{array}$ & $26.4 \%(145)$ \\
\hline Did not need any information & $22.4 \%(123)$ \\
\hline $\begin{array}{l}\text { Did not have time due to other 'life' } \\
\text { demands }\end{array}$ & $8.9 \%(49)$ \\
\hline Did not know what questions to ask & $6.6 \%(36)$ \\
\hline $\begin{array}{l}\text { Did not know where to look for } \\
\text { information }\end{array}$ & $6.0 \%(33)$ \\
\hline Other reason(s) & $6.0 \%(33)$ \\
\hline Did not have access to info sources & $2.6 \%(14)$ \\
\hline
\end{tabular}

Table 1. Reason For Not Looking For Information Prior to Coming to the Emergency Department

\section{Information Needs}

Over one-third of parents $(38.8 \%, n=348)$ looked for information prior to the visit. Parents whose annual household income was less than $\$ 25,000$ were statistically significantly less likely to look for information before coming to an $\mathrm{ED}\left(\beta=-0.713 ; \mathrm{SE}=0.207\right.$; Wald $\chi^{2}=$ $11.818 ; p=0.001)$, as were parents who regularly took their child for a regular health check-up $(\beta=-0.247$; $\mathrm{SE}=0.098$; Wald $\left.\chi^{2}=6.416 ; p=0.011\right)$. Of those 348 parents, 337 answered the question "What type of information did you look for?" including ranking the responses provided and rating the helpfulness of the information (see Table 2).

\begin{tabular}{|c|c|c|}
\hline Information Type & $\begin{array}{l}\% \text { (n) } \\
n=337\end{array}$ & $\begin{array}{l}\text { Mean } \\
\text { Helpfulness } \\
\text { Rating Scale } 1 \\
\text { to } 10 \text { (n; SD) }\end{array}$ \\
\hline $\begin{array}{l}\text { Specific symptoms } \\
\text { exhibited }\end{array}$ & $\begin{array}{l}69.1 \% \\
(233)\end{array}$ & $\begin{array}{l}7.4(228 ; \mathrm{SD} \\
2.1)\end{array}$ \\
\hline To determine severity & $\begin{array}{l}43.0 \% \\
(145)\end{array}$ & $\begin{array}{l}7.4(140 ; \mathrm{SD} \\
2.3)\end{array}$ \\
\hline $\begin{array}{l}\text { General information about } \\
\text { an illness/condition }\end{array}$ & $\begin{array}{l}38.9 \% \\
(131)\end{array}$ & $\begin{array}{l}7.1(129 ; \mathrm{SD} \\
2.2)\end{array}$ \\
\hline To determine next steps & $\begin{array}{l}27.3 \% \\
(92)\end{array}$ & $\begin{array}{l}7.2(90 ; \mathrm{SD} \\
2.4)\end{array}$ \\
\hline $\begin{array}{l}\text { Where to go for medical } \\
\text { advice/attention }\end{array}$ & $\begin{array}{l}15.1 \% \\
(51)\end{array}$ & $\begin{array}{l}7.7(50 ; \mathrm{SD} \\
2.1)\end{array}$ \\
\hline Which hospital to go to & $4.5 \%(15)$ & $\begin{array}{l}7.2(15 ; \mathrm{SD} \\
2.7)\end{array}$ \\
\hline Child care options & $3.0 \%(10)$ & $\begin{array}{l}7.0(10 ; \mathrm{SD} \\
1.9)\end{array}$ \\
\hline $\begin{array}{l}\text { Location/directions for } \\
\text { hospital }\end{array}$ & $2.4 \%(8)$ & $8.6(7 ; \mathrm{SD} 1.2)$ \\
\hline $\begin{array}{l}\text { Parking information for } \\
\text { hospital }\end{array}$ & $2.1 \%(7)$ & $5.4(8 ;$ SD 2.3) \\
\hline Transportation options & $1.2 \%(4)$ & $7.8(4 ;$ SD 2.6) \\
\hline $\begin{array}{l}\text { Nearby or nighttime } \\
\text { pharmacies }\end{array}$ & $0.9 \%(3)$ & $5.3(3 ; \mathrm{SD} 1.5)$ \\
\hline Other information & $0.9 \%(3)$ & $6.0(2 ; \mathrm{SD} 0.0)$ \\
\hline
\end{tabular}

The most common type of information searched for addressed specific symptoms, severity of illness, or other details about a condition or illness. "Other" information included when to see a doctor $(n=2)$ and "What to do when you keeping hitting dead ends and get no real answer" $(n=1)$. Parents were asked to rate the helpfulness of the information they located before coming to the ED on a 
sliding scale from 1 (least helpful), to 10 (most helpful). Generally, information related to the child's illness or condition was rated as being helpful, while information about the logistics of taking a child to the ED varied widely. Overall, very few parents mentioned looking for logistical information (i.e., parking, hospital location, etc.) and their ratings of the helpfulness of this information varied widely.

Parents were also asked, "Do you have all the information you need about bringing your child into the emergency department?" They rated these responses on a sliding scale from 1 (insufficient information), to 10 (sufficient information). Overall, the information obtained was sufficient, with 7.0 the lowest rating provided (see Table 3).

\begin{tabular}{|l|l|}
\hline Information Type & $\begin{array}{l}\text { Mean Sufficiency } \\
\text { Rating Scale 1 to 10 } \\
\text { (n; SD) }\end{array}$ \\
\hline $\begin{array}{l}\text { When to come to the } \\
\text { emergency department }\end{array}$ & $7.8(867 ;$ SD 2.3) \\
\hline Medical/health information & $7.8(871 ;$ SD 2.3$)$ \\
\hline Coming to the hospital & $7.7(873 ;$ SD 2.7$)$ \\
\hline $\begin{array}{l}\text { Strategies to comfort/distract } \\
\text { sick child }\end{array}$ & $7.3(871 ;$ SD 2.6) \\
\hline $\begin{array}{l}\text { Strategies to deal with own } \\
\text { stress/anxiety }\end{array}$ & $7.2(874 ;$ SD 2.7) \\
\hline $\begin{array}{l}\text { About the emergency } \\
\text { department }\end{array}$ & $7.0(868 ;$ SD 2.8) \\
\hline
\end{tabular}

Table 3. Sufficiency of Information About Bringing Child to Emergency Department

The questionnaire also asked, "What type of information do you need (that you currently do not have) about being in the emergency department with this child?" In total, 883 parents answered this question, ranking the options provided (see Table 4). Answers ranged from discussions of particularities of conditions, care instructions, how to talk about the condition, as well as information about the ED itself. "Other" information needs related to wait times $(n=5)$, not receiving treatment $(n=1)$, and reasons for children not getting preference in ED care $(n=1)$.

As the age of the parent increased, parents were significantly less likely to indicate that treatment information $\left(\beta=-0.115\right.$; $\mathrm{SE}=0.053$; Wald $\chi^{2}=4.681 ; p=$ $0.031)$, strategies to comfort/distract the child $(\beta=-0.184$; $\mathrm{SE}=0.075$; Wald $\left.\chi^{2}=5.986 ; p=0.014\right)$, and information about the $\operatorname{ED}\left(\beta=-235 ; \mathrm{SE}=0.088\right.$; Wald $\chi^{2}=7.211 ; p=$ $0.007)$ were important information needs.

In instances where the visit to the ED was related to a known medical condition, parents were significantly less likely to identify needing strategies to talk to the child about their illness/condition $\left(\beta=-0.963 ; \mathrm{SE}=0.185 ;\right.$ Wald $\chi^{2}=$ $27.022 ; p=<0.0001$ ), or strategies to deal with other life demands $\left(\beta=-0.813\right.$; $\mathrm{SE}=0.193$; Wald $\chi^{2}=17.853 ; p=$ $<0.0001)$, as vital information needs.

Additionally, parents whose families lived below the poverty line (i.e., annual household income below \$25,000) were significantly less likely to identify care instructions as a primary information need $(\beta=-0.527$; $\mathrm{SE}=0.205$; Wald $\left.\chi^{2}=6.586 ; p=0.010\right)$.

\begin{tabular}{|c|c|}
\hline Information Needed & $\begin{array}{l}\%(n) \\
n=883\end{array}$ \\
\hline Explanation of illness/condition & $47.0 \%(415)$ \\
\hline Treatment information & $44.4 \%(392)$ \\
\hline Care instructions & $42.1 \%(372)$ \\
\hline Reasons for child's illness/condition & $36.2 \%(320)$ \\
\hline $\begin{array}{l}\text { When to come to the emergency } \\
\text { department }\end{array}$ & $28.3 \%(250)$ \\
\hline How to comfort and/or distract their child & $15.3 \%(135)$ \\
\hline $\begin{array}{l}\text { Information about the emergency } \\
\text { department itself }\end{array}$ & $11.4 \%(101)$ \\
\hline $\begin{array}{l}\text { Information about how to deal with 'life } \\
\text { demands' while child is in the emergency } \\
\text { department }\end{array}$ & $8.5 \%(75)$ \\
\hline $\begin{array}{l}\text { How to talk to their child about the } \\
\text { illness/condition }\end{array}$ & $8.3 \%(73)$ \\
\hline $\begin{array}{l}\text { Information about coming to the } \\
\text { emergency department }\end{array}$ & $8.0 \%(71)$ \\
\hline $\begin{array}{l}\text { How to talk to others about their child's } \\
\text { illness/condition }\end{array}$ & $5.2 \%(46)$ \\
\hline Other information & $0.9 \%(8)$ \\
\hline
\end{tabular}

Table 4. Information Needs of Parents Seeking Care For Their Child in the Emergency Department

\section{Information Source Use and Preference}

Of the 348 parents (38.8\%) who looked for information before coming to the ED, 345 responded to the question "Where did you look for [information related to your child's health situation prior to coming to the emergency department today]?" The data in Table 5 indicate that the internet was the most commonly used resource, followed by talking to health professionals over the phone or in person.

The "Other sources" parents listed include books $(n=4)$ and trusted professionals, including a pharmacist $(n=2)$, daycare workers $(n=1)$, and school teacher/counselor $(n=1)$. 


\begin{tabular}{|l|l|}
\hline Information Source Type & $\begin{array}{l}\text { \% (n) } \\
\mathbf{n}=\mathbf{3 4 5}\end{array}$ \\
\hline Internet search engine & $44.1 \%(152)$ \\
\hline $\begin{array}{l}\text { Over the telephone from health } \\
\text { professional }\end{array}$ & $31.9 \%(110)$ \\
\hline $\begin{array}{l}\text { In-person from a health professional (not } \\
\text { in the emergency department) }\end{array}$ & $29.9 \%(103)$ \\
\hline Family/friends & $20.3 \%(70)$ \\
\hline Specific medical/health websites & $12.5 \%(43)$ \\
\hline $\begin{array}{l}\text { Parents of child(ren) with same } \\
\text { illness/condition }\end{array}$ & $6.7 \%(23)$ \\
\hline Other sources & $4.6 \%(16)$ \\
\hline Medical information sheet/brochure & $3.8 \%(13)$ \\
\hline Smartphone 'app' & $3.5 \%(12)$ \\
\hline Social media & $2.3 \%(8)$ \\
\hline The library & $1.2 \%(4)$ \\
\hline
\end{tabular}

Table 5. Information Sources Used Before Coming to Emergency Department

When asked "How do you normally find health information that you need to care for your child?" parents ranked talking to people and using the internet highly (see Table 6). Some of the "Other methods" parents used, for example, were print materials $(\mathrm{n}=7)$, nurse websites $(\mathrm{n}=1)$, and previous experience $(n=9)$.

\begin{tabular}{|l|l|}
\hline Information Source Type & $\begin{array}{l}\text { \% (n) } \\
\mathbf{n}=\mathbf{8 9 7}\end{array}$ \\
\hline Talking to trusted professionals & $68.7 \%(616)$ \\
\hline Internet search engine & $52.5 \%(471)$ \\
\hline Talking to family and friends & $50.3 \%(451)$ \\
\hline Smartphone 'apps' & $8.6 \%(77)$ \\
\hline Contacting specific agencies & $7.9 \%(71)$ \\
\hline Reading newspaper/magazines & $6.8 \%(61)$ \\
\hline Social media & $4.0 \%(36)$ \\
\hline At the library & $3.2 \%(29)$ \\
\hline Other methods & $2.1 \%(19)$ \\
\hline
\end{tabular}

Table 6. Information Sources Typically Used When Looking For Child Health Information

As parents' age and highest level of education increased, they were less likely to identify talking with family and friends as an important information source typically used for child health information $(\beta=-0.170$; $\mathrm{SE}=0.053$; Wald $\chi^{2}=10.361 ; p=0.001$ and $\beta=-0.103 ; \mathrm{SE}=0.051 ;$ Wald $\chi^{2}$ $=3.995 ; p=0.046$ respectively). As parents' highest level of education increased, so did their likelihood to indicate the importance of talking to a trusted healthcare professional when typically searching for information $(\beta=$ 0.154 ; $\mathrm{SE}=0.056$; Wald $\chi^{2}=7.607 ; p=0.006$ ). This was also the case for parents who regularly took their child for health check-ups $\left(\beta=0.290\right.$; $\mathrm{SE}=0.102$; Wald $\chi^{2}=8.007$; $p=0.005$ ). Participating parents were also asked, "How would you like to learn new information about your child's illness/condition?" and to rank the options provided. Table 7 shows that the majority of parents ranked talking to health care professionals in-person highly. Interestingly, receiving new information via a medical sheet or brochure was also listed as an information source preference by approximately $32.3 \%(\mathrm{n}=285)$ of parents; this is slightly more than parents who preferred to receive new information from the internet, at $28.8 \% \quad(\mathrm{n}=254)$. The "other information source" preferences listed by parents were a parenting book $(\mathrm{n}=1)$ and a doctor (format of visit not specified) $(n=1)$.

\begin{tabular}{|l|l|}
\hline Information Source Preference & $\begin{array}{l}\text { \% (n) } \\
\mathbf{n = 8 8 2}\end{array}$ \\
\hline In-person from a healthcare professional & $73.5 \%(648)$ \\
\hline Medical information sheet/brochure & $32.3 \%(285)$ \\
\hline $\begin{array}{l}\text { Over the telephone from a healthcare } \\
\text { professional }\end{array}$ & $30.5 \%(269)$ \\
\hline Internet search engine & $28.8 \%(254)$ \\
\hline Specific medical/health websites & $25.4 \%(224)$ \\
\hline Family/friends & $12.4 \%(109)$ \\
\hline $\begin{array}{l}\text { Parents of child(ren) with same } \\
\text { illness/condition }\end{array}$ & $12.2 \%(108)$ \\
\hline Smartphone 'app' & $10.4 \%(92)$ \\
\hline Email & $8.8 \%(78)$ \\
\hline Storybooks about families & $5.7 \%(50)$ \\
\hline $\begin{array}{l}\text { Social media (i.e., Facebook, Twitter, } \\
\text { YouTube) }\end{array}$ & $3.9 \%(34)$ \\
\hline Text message & $3.6 \%(32)$ \\
\hline The library & $2.3 \%(20)$ \\
\hline Other sources & $0.2 \%(2)$ \\
\hline
\end{tabular}

Table 7. Information Source Preferences For Receiving New Child Healthcare Information

When speaking, in-person, to healthcare professionals, parents preferred to receive information from a doctor, whether from their family doctor $(51.5 \%, \mathrm{n}=333)$, pediatrician $(48.5 \%, \mathrm{n}=314)$, or a general physician $(32.5 \%$, $\mathrm{n}=210$ ). In examining source preferences, parents from 
families with annual household incomes below $\$ 25,000$ were significantly less likely to want to receive new information over the phone with a health professional $(\beta=$ $0.184 ; \mathrm{SE}=0.085$; Wald $\left.\chi^{2}=4.690 ; p=0.030\right)$. As parents' ages increased, they were less likely to prefer receiving new child health information from family and friends $(\beta=$ 0.357; $\mathrm{SE}=0.092$; Wald $\left.\chi^{2}=15.108 ; p=0.000\right)$, from parents of children with a similar illness $(\beta=-0.215$; $\mathrm{SE}=$ 0.085 ; Wald $\left.\chi^{2}=6.453 ; p=0.011\right)$, or from a smartphone app $\left(\beta=-0.222 ; \mathrm{SE}=0.094 ;\right.$ Wald $\left.\chi^{2}=5.640 ; p=0.018\right)$. As parents' level of education increased, they were more likely to indicate a preference for receiving new child health information from specific websites $(\beta=0.166$; $\mathrm{SE}=$ 0.059 ; Wald $\left.\chi^{2}=7.990 ; p=0.005\right)$. The opposite was true of parents whose children had regular check-ups; they were less likely to identify specific websites as future sources $(\beta$ $=-0.231 ; \mathrm{SE}=0.108$; Wald $\chi^{2}=4.618 ; p=0.032$ ).

\section{DISCUSSION}

The results show most parents do not search for information before going to emergency departments (ED); almost 50\% of parents who did not search for information said they did not have time to do so, while almost $25 \%$ of those who did not search for information preferred to get information at the ED itself. While much of the literature presumes health consumers will seek information, this does not necessarily extend to emergent situations. For many parents coping with a child's health emergency, information seeking begins at the ED. This may reflect parental preferences for receiving information from reliable sources (Guillaume \& Bath, 2004; C. Jackson et al., 2008) and in-person sources (R. Jackson et al., 2008; Johnson \& Case, 2012). However, this may also relate to the fact that quick (and even life or death) decisions must be made in the immediate moment of a health crisis. In these situations, information seeking is a lower priority for parents than getting to the ED quickly. Parents who looked for information prior to arriving in the ED most frequently looked for information about symptoms, severity, and what to do next. While fewer parents looked for logistical information about taking their child to the hospital, being able to find correct logistical information when needed is important. Parents reported that, generally, the information they found prior to coming to the ED was "helpful" and "sufficient," while usefulness of logistical information varied widely. This is important for information organization and web design, as health information needs are not limited to health content; web developers, librarians, and other information professionals must ensure that information is easily accessible to facilitate access to emergent care. Additional research on the usability of hospital websites is also warranted.

Before coming to the ED, parents indicated that the most frequently used information source was the internet, followed by talking to healthcare professionals and others in various ways (e.g., telephoning or speaking in person to healthcare professionals; speaking to family and friends).
These results are in keeping with other studies that show: 1) that the vast majority of parents prefer to contact people as information sources on child health; and 2), when contacting health professionals, parents prefer to do so in person (see R. Jackson et al., 2008; Johnson \& Case, 2012). In this study, approximately only one-third of parents indicated a desire to receive new child health information from the internet, which is slightly less than those indicating a preference for health brochures. This is an interesting finding, as parents did not use health brochures as an information source before taking their child to the ED.

Demographic details provide insight on parents' health information needs, information source use, and preferences. Parents with an annual household income of less than $\$ 25,000$ were less likely to look for information before coming to the ED and less likely to indicate needing care instructions. They also indicated they did not want to receive new child health information by speaking with healthcare professionals on the phone. As parents' level of education increased they were less likely to typically receive child health information from family and friends and more likely to note the importance of talking, in person, to healthcare professionals. Parents with higher levels of education were also more likely to want to receive new child health information from specific health or medical websites. These findings reinforce published results in other health studies that individuals prefer interpersonal and authoritative information channels (Johnson \& Case, 2012). As parents' ages increased, they were less likely to indicate a need for information about treatment, strategies to distract or comfort their child, or information about the ED. They were also less likely to typically seek child health information from family and friends. Rather, as parents got older, they were less likely to express a preference for receiving new child health information from family and friends, parents of a child with a similar illness, or a smartphone app. These findings support existing literature showing that demographic factors play an important role in parents' information behavior (C. Jackson et al., 2008; Lipstein et al., 2012; Walker, 2012). The implications of these findings are that using a 'one size fits all' approach to the provision of health information in ED (and other health) contexts will not meet the needs of all health consumers.

\section{CONCLUSION}

Overall, emergent health situations are complex in nature, reflecting situations that are stressful and where individuals' information needs may be unclear. In this study, the majority of parents did not search for information before taking their child to the emergency department. Rather, parents were concerned with getting to the ED quickly, preferring to gather information once on site, primarily from physicians. Parents who searched for information were most frequently looking for information on a child's symptoms and severity to make informed decisions, including whether/when to seek emergency care. 
Parents were satisfied with and found helpful the health information they obtained; however, they were much less satisfied and found less helpful information about the logistics of obtaining emergency care. Further research is required to better understand the information behavior of parents (and other caregivers) in emergent health situations, as well as the child patients themselves. There is also a need for more research on the information behavior of parents, both in general terms and in their roles as proxy information seekers. This study provides results on what parents do, including preferences for sources and technology use. More research is needed to explore how information shapes decisions made during emergency situations, as well as the usefulness of that information from the child's perspective.

\section{ACKNOWLEDGMENTS}

This study was funded by Networks of Centres of Excellence Canada as part of Translating Emergency Knowledge for Kids (TREKK) (Dr. Shannon D. Scott, codirector; Dr. Lisa M Given, co-lead, Information Needs Assessment). The Women and Children's Health Research Institute (University of Alberta) and the Faculty of Education (Charles Sturt University) provided further funding. The authors thank all members of TREKK including Drs. Terry Klassen, Lisa Hartling, Mona Jabbour, and David Johnson. The authors also thank the parents and hospital staff for their time in participating in this study.

\section{REFERENCES}

Abrahamson, J. A., \& Fisher, K. E. (2007). "What's past is prologue': Towards a general model of lay information mediary behaviour. In Proceedings of the Sixth International Conference on Conceptions of Library and Information Science. Retrieved from http://www.informationr.net/ir/12-4/colis/colis15.html

Albrecht, L., Hartling, L. \& Scott, S.D. (in press). Pediatric acute gastroenteritis: Understanding caregivers' experiences and information needs. Canadian Journal of Emergency Medicine.

Al-Daihani, S. M., \& Al-Ateeqi, H. I. (2015). Parents of children with disabilities in Kuwait: A study of their information seeking behaviour. Health Information \& Libraries Journal, 32(2), 131-142. doi:10.1111/hir.12102

Ayatollahi, H., Bath, P. A., \& Goodacre, S. (2013). Information needs of clinicians and non-clinicians in the Emergency Department: a qualitative study. Health Information \& Libraries Journal, 30(3), 191-200. doi:10.1111/hir.12019

Bernhardt, J. M., \& Felter, E. M. (2004). Online pediatric information seeking among mothers of young children: Results from a qualitative study using focus groups. Journal of Medical Internet Research, 6(1), e7. http://doi.org/10.2196/jmir.6.1.e7

Bianco, A., Zucco, R., Nobile, C. G. A., Pileggi, C., \& Pavia, M. (2013). Parents seeking health-related information on the Internet: Cross-sectional study. Journal of Medical Internet Research, 15(9), e204. http://doi.org/10.2196/jmir.2752
Bouche, G., \& Migeot, V. (2008). Parental use of the Internet to seek health information and primary care utilisation for their child: A cross-sectional study. $B M C$ Public Health, 8(1), 300. doi:10.1186/1471-2458-8-300

Canadian Public Health Association. (2008). A vision for a health literate Canada: Report of the expert panel on health literacy. Ottawa, ON: Canadian Public Health Association. $\quad$ Retrieved from http://www.cpha.ca/uploads/portals/h-1/report_e.pdf

Case, D. O. (2012). Research by social role and demographic group. In Looking for information: A survey of research on information seeking, needs, and behavior (3rd ed.) (pp. 325-364). Bingley, UK: Emerald.

DeLuca, J. M., Kearney, M. H., Norton, S. A., \& Arnold, G. L. (2012). Internet use by parents of infants with positive newborn screens. Journal of Inherited Metabolic Disease, 35(5), 879-884.

Devolin, M., Phelps, D., Duhaney, T., Benzies, K., Hildebrandt, C., Rikhy, S., \& Churchill, J. (2013). Information and support needs among parents of young children in a region of Canada: A cross-sectional survey. Public Health Nursing, 30(3), 193-201. doi:10.1111/phn.12002

Dewdney, P., Harris, R. M., \& Lockerby, C. (1996). Meeting the information needs of battered women: Responsibilities and roles for library and information science. The Reference Librarian, 25(53), 27-45. doi:10.1300/J120v25n53_04

Diviani, N., van den Putte, B., Giani, S., \& van Weert, J. C. (2015). Low Health Literacy and Evaluation of Online Health Information: A Systematic Review of the Literature. Journal of Medical Internet Research, 17(5), e112. http://doi.org/10.2196/jmir.4018

Falk, A.-C., von Wendt, L., \& Klang, B. (2008). Informational needs in families after their child's mild head injury. Patient Education and Counseling, 70(2), 251-255. doi:10.1016/j.pec.2007.10.001

Fisher, H. R. (2001). The needs of parents with chronically sick children: A literature review. Journal of Advanced Nursing, 36(4), 600-607.

Fisher, K. E., \& Landry, C. F. (2007). Understanding the information behavior of stay-at-home mothers through affect. In D. Nahl \& D. Bilal (Eds.), Information and emotion: The emergent affective paradigm in information behavior research and theory (pp. 211-234). Medford, NJ: Information Today, Inc.

Guillaume, L. R., \& Bath, P. A. (2004). The impact of health scares on parents' information needs and preferred information sources: a case study of the MMR vaccine scare. Health Informatics Journal, 10(1), 5-22. doi:10.1177/146045804040664

Genuis, S. K. (2012). Constructing "sense" from evolving health information: A qualitative investigation of information seeking and sense making across sources. Journal of the American Society for Information Science and Technology, 63(8), 1553-1566. doi:10.1002/asi.22691 
Hersberger, J. (2001). Everyday information needs and information sources of homeless parents. New Review of Information Behaviour Research, 2, 119-134.

Hope, P., \& Zhang, X. (2015). Examining user satisfaction with single sign-on and computer application roaming within emergency departments. Health Informatics Journal, 21(2), 107-119.

Hummelinck, A., \& Pollock, K. (2006). Parents' information needs about the treatment of their chronically ill child: A qualitative study. Patient Education and Counseling, 62(2),
doi:10.1016/j.pec.2005.07.006

Ingram, J., Cabral, C., Hay, A. D., Lucas, P. J., Horwood, J., \& others. (2013). Parents' information needs, selfefficacy and influences on consulting for childhood respiratory tract infections: A qualitative study. $B M C$ Family Practice, 14(1). Retrieved from http://www.biomedcentral.com/1471-2296/14/106

Jackson, C., Cheater, F. M., \& Reid, I. (2008). A systematic review of decision support needs of parents making child health decisions. Health Expectations, 11(3), 232-251. doi:10.1111/j.1369-7625.2008.00496.x

Jackson, R., Baird, W., Davis-Reynolds, L., Smith, C., Blackburn, S., \& Allsebrook, J. (2008). Qualitative analysis of parents' information needs and psychosocial experiences when supporting children with health care needs. Health Information and Libraries Journal, 25(1), 31-37. doi:10.1111/j.1471-1842.2007.00736.x

Johnson, J. D. \& Case, D. O. (2012). Health information seeking. New York: Peter Lang Publishing Inc.

Johnson, K. B., Unertl, K. M., Chen, Q., Lorenzi, N. M., Nian, H., Bailey, J., \& Frisse, M. (2011). Health information exchange usage in emergency departments and clinics: the who, what, and why. Journal of the American Medical Informatics Association, 18(5), 690697. doi:10.1136/amiajnl-2011-000308

Joshi, A., Weng, W., Lichenstein, R., Arora, M., \& Sears, A. (2009). Prospective tracking of a pediatric emergency department e-kiosk to deliver asthma education. Health Informatics Journal, 15(4), 282-295. doi:10.1177/1460458209345899

Koehly, L. M., Peters, J. A., Kenen, R., Hoskins, L. M., Ersig, A. L., Kuhn, N. R., ... Greene, M. H. (2009). Characteristics of health information gatherers, disseminators, and blockers within families at risk of hereditary cancer: Implications for family health communication interventions. American Journal of Public Health, 99(12), 2203-2209.

Koonce, T. Y., Giuse, N. B., \& Storrow, A. B. (2011). A pilot study to evaluate learning style-tailored information prescriptions for hypertensive emergency department patients. Journal of the Medical Library Association: JMLA, 99(4), 280-289. doi:10.3163/1536-5050.99.4.005

Lipstein, E. A., Brinkman, W. B., \& Britto, M. T. (2012). What is known about parents' treatment decisions? A narrative review of pediatric decision making. Medical
Decision Making, 32(2), 246-258. doi:10.1177/0272989X11421528

Lopatovska, I., \& Smiley, B. (2014). Proposed model of information behaviour in crisis: the case of Hurricane Sandy. Information Research, 19(1), 19-1. Retrieved from www.informationr.net/ir/19-1/paper610.html

Lu, Y. (2007). The human in human information acquisition: Understanding gatekeeping and proposing new directions in scholarship. Library \& Information Science Research, 29(1), 103-123. doi:10.1016/j.lisr.2006.10.007

McKenzie, P. J. (2003). A model of information practices in accounts of everyday-life information seeking. Journal of Documentation, 59(1), 19-40. doi:10.1108/00220410310457993

Nicholas, D., \& Marden, M. (1998). Parents and their information needs A case study: Parents of children under the age of five. Journal of Librarianship and Information Science, 30(1), 35-48.

Pang, N. (2014). Crisis-based information seeking: monitoring versus blunting in the information seeking behavior of working students during the Southeast Asian Haze Crisis. In Proceedings of ISIC 2014: The information behavior conference, 2-5 September. Retrieved from www.informationr.net/ir/19. 4/isic/isic14.html

Reddy, M. C., \& Spence, P. R. (2008). Collaborative information seeking: A field study of a multidisciplinary patient care team. Information Processing \& Management, 44(1), 242-255. doi:10.1016/j.ipm.2006.12.003

van Velsen, L., van Gemert-Pijnen, J. E. W. ., Beaujean, D. J. M. ., Wentzel, J., \& van Steenbergen, J. E. (2012). Should health organizations use Web 2.0 media in times of an infectious disease crisis? An in-depth qualitative study of citizens' information behavior during an EHEC outbreak. Journal of Medical Internet Research, 14(6), e181. http://doi.org/10.2196/jmir.2123

Wainstein, B. K., Sterling-Levis, K., Baker, S. A., Taitz, J., \& Brydon, M. (2006). Use of the Internet by parents of paediatric patients. Journal of Paediatrics and Child Health, 42(9), 528-532.

Walker, C. G. (2009). Seeking Information: A study of the use and understanding of information by parents of young children. Journal of Information Literacy, 3(2), 53-63.

Westbrook, L. (2008a). E-government support for people in crisis: An evaluation of police department website support for domestic violence survivors using "person-insituation" information need analysis. Library \& Information Science Research, 30(1), 22-38.

Westbrook, L. (2008b). Understanding crisis information needs in context: The case of intimate partner violence survivors. The Library Quarterly, 78(3), 237-261.

Westbrook, L. (2009). Crisis information concerns: Information needs of domestic violence survivors. Information Processing \& Management, 45(1), 98-114. 